\title{
The pathological features of hip abductor tendon tears - a cadaveric study
}

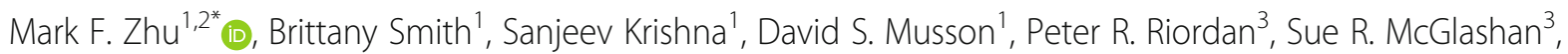
Jillian Cornish ${ }^{1}$ and Jacob T. Munro ${ }^{1,2}$

\begin{abstract}
Background: The hip abductors are crucial in maintaining pelvic stability. Tears in these tendons are common and often debilitating. There is uncertainty regarding both the histological and macroscopic features of hip abductor tears. This study aims to clarify both the macroscopic and microscopic features of the tendon and enthesis in hip abductor tendon tears.

Methods: Thirty-six cadavers with an average age of 81 were dissected, and the hip abductor mechanisms removed en-bloc. The presence, location and size of the tears were recorded and analysed. The samples were processed into histological blocks and viewed using both transmitted and polarised light. Tendon histology was graded using the modified Movin's score in three sections (deep, middle and superficial layers) and the enthesis graded separately using 5-point criteria. Analysis of variance was used to confirm histological features associated with tears.
\end{abstract}

Results: Tears were found in 24 of 36 samples (67\%). The most common finding was an isolated tear in the gluteus minimus (46\%), followed by concurrent gluteus medius and gluteus minimus tears (33\%). Histology revealed significantly more degeneration in both the tendon $(p=0.0005)$ and enthesis $(p=0.0011)$ when tears were present. Furthermore, these changes were concentrated in the deeper layers of the tendon $(p=0.0002)$ and enthesis ( $p=0.003)$.

Conclusion: This study demonstrated degeneration as the primary pathology underlying hip abductor tendon tears. Degenerative changes occur in both the tendon and enthesis, with the deeper layers predominantly affected. These findings are important for guiding surgical repair techniques and to aid the development of novel materials and biologics.

Keywords: Hip abductor, Tendinopathy, Histology, Degeneration

\footnotetext{
* Correspondence: mzhu031@aucklanduni.ac.nz

'Bone and Joint Laboratory, University of Auckland, 85 Park Road, Grafton 1023, New Zealand

2Department of Orthopaedic Surgery, Auckland City Hospital, 2 Park Road Grafton, New Zealand

Full list of author information is available at the end of the article
}

(c) The Author(s). 2020 Open Access This article is licensed under a Creative Commons Attribution 4.0 International License, which permits use, sharing, adaptation, distribution and reproduction in any medium or format, as long as you give appropriate credit to the original author(s) and the source, provide a link to the Creative Commons licence, and indicate if changes were made. The images or other third party material in this article are included in the article's Creative Commons licence, unless indicated otherwise in a credit line to the material. If material is not included in the article's Creative Commons licence and your intended use is not permitted by statutory regulation or exceeds the permitted use, you will need to obtain permission directly from the copyright holder. To view a copy of this licence, visit http://creativecommons.org/licenses/by/4.0/. The Creative Commons Public Domain Dedication waiver (http://creativecommons.org/publicdomain/zero/1.0/) applies to the data made available in this article, unless otherwise stated in a credit line to the data. 


\section{Background}

The gluteus medius and minimus are commonly referred to as the hip abductors. Tears of the hip abductor tendons are increasingly recognised as causes for chronic hip dysfunction and pain [1-4]. In the age group requiring hip arthroplasty, the incidence is approximately 20 to $25 \%$ [5-8].

Despite its prevalence, there is limited literature on the pathological features of disease $[9,10]$. While the majority of surgical and imaging studies have described tears in the anterior gluteus medius, tears of the gluteus minimus and posterior gluteus medius have also been described [11]. Microscopically, degenerative tendinopathy is thought to be the underlying pathological change in hip abductor tendon tears. However, no previous studies were able to quantify and describe these changes in detail $[1,11]$.

In recent years, studies have attempted to improve the repair of both complete and partial tears of gluteus medius and minimus with limited success [12-14]. Conservative treatment with education and exercise programs is ineffective in patients with hip instability and full thickness tears $[15,16]$.

Further understanding of both the macroscopic and microscopic pathology are required to clarify the mechanism of failure and allow for more effective surgical repair. An understanding of the microscopic pathology will provide the basis for designing novel materials and biologics to improve repair outcomes. Therefore, the aim of this study is to use cadaveric tissues to determine the macro- and microscopic pathology associated with tears of the hip abductor tendons.

\section{Methods}

\section{Specimens}

Thirty-six hips in 30 cadavers (15 females and 15 males) were obtained from the Human Anatomy Lab, Department of Anatomy and Medical Imaging, University of Auckland. The cadavers were formalin-embalmed using Dodge anatomical mix (Dodge Chemical Corporation Incorporated). All tissue was donated with informed consent in compliance with the Human Tissue Act 2008 for teaching and research purposes. The average age of the cadavers was 80.9 years. No cadavers with a history of hip surgery on the dissected side were included in the study.

\section{Dissection, macroscopic examination and tissue processing}

In all cadavers, the gluteus medius and minimus muscles and their attachment to the greater trochanter were removed en-bloc. Specimens were dissected to separate the gluteus medius from minimus. All superficial fat was removed, and the trochanteric bursa was carefully excised. The specimens were then examined macroscopically for tears in both the gluteus medius and minimus tendons. The presence, location (at the lateral facet or supero-posterior insertion for gluteus medius), size and type of tear (partial or complete) were recorded after careful dissection by a senior arthroplasty surgeon (JM) and the lead author (MZ). The width of the tear was measured parallel to the long axis of the footprint using a digital calliper. Other pathological features were noted; gross fatty atrophy of the muscle, bony changes at the footprint and tendon delamination.

Following macroscopic examination, the gluteus medius and minimus were dissected to capture the tendon, enthesis and its bony attachment (Fig. 1). For the gluteus medius, the sample was further split into the lateral and posterior insertions at the lateral and supero-posterior facets $[17,18]$. These processed tissue blocks were then post fixed in $10 \%$ neutral buffered formalin for 5 days and decalcified in $10 \%$ formic acid for 14 days at $4{ }^{\circ} \mathrm{C}$. Following decalcification, the tissue blocks were subjected to a routine dehydration process in $70 \%$ ethanol

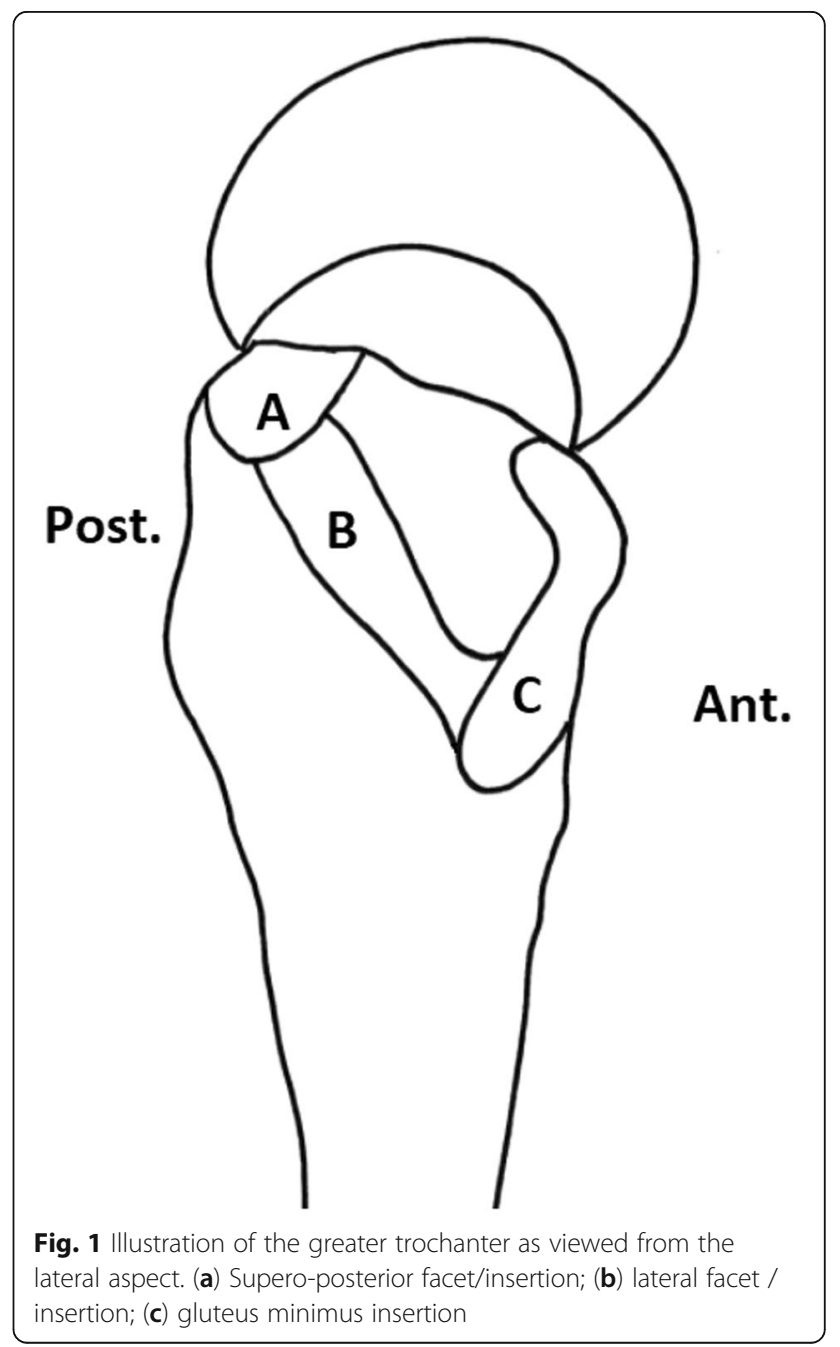


and embedded in paraffin wax. Sagittal sections of the distal $2 \mathrm{~cm}$ of tendon and the tendon bone junction were cut at $7 \mu \mathrm{m}$ at $500 \mu \mathrm{m}$ intervals throughout the tissue block. A total of 8 slides were obtained per sample and were stained using Haematoxylin and Eosin (H\&E).

\section{Histological grading}

Samples of the lateral and supero-posterior insertion of gluteus medius and the gluteus minimus were processed and graded separately. The slides of tissue were viewed under a microscope using transmitted and polarised light. The boundary between the tendon and enthesis was demarcated by the last longitudinal column of chondrocytic cells [19]. For the lateral gluteus medius insertion, the deep, middle and superficial layers of the tendon and enthesis were graded separately to identify differences in degeneration between the layers (Fig. 2). In all samples, the tendon was graded using the Modified Movin's score (Additional file 1: Appendix 1) while the enthesis was graded using a 5 point scoring system derived from previous studies (Additional file 1: Appendix 2) [20-25]. In samples with complete tears, the region immediately adjacent to the tear was

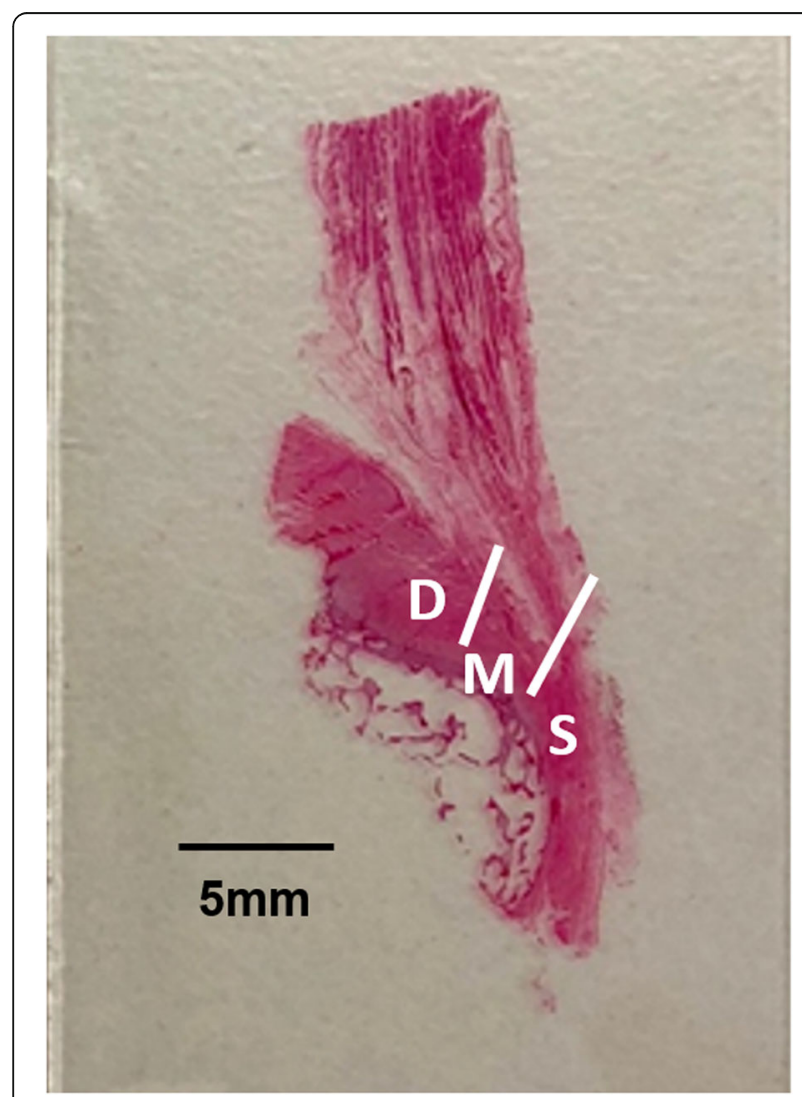

Fig. 2 Cross section of anterior gluteus medius sample stained with H\&E indicating the deep (a), middle (b) and superficial (c) areas for grading evaluated, as it would be otherwise impossible to grade both the tendon and enthesis. A minimum of 3 slides were viewed for each sample. For the lateral gluteus medius insertion, an overall score of the sample was obtained by averaging the score in the three layers. All samples were graded independently by two individuals with experience in bone and tendon research and reviewed by a musculoskeletal pathologist.

\section{Statistical analysis}

All statistical tests were performed using GraphPad PRIS M software (GraphPad Software, San Diego, CA). Comparisons of macroscopic features were performed using one-way analysis of variance where appropriate.

For microscopic features, degeneration scores were compared using Mann-Whitney's U test between two groups and by one-way analysis of variance for three or more groups. Categorical variables were analysed using Fisher's exact test. Interactions were assessed using twoway analysis of variance. Bonferroni correction was used when multiple comparisons were made. A $p$ value $<0.05$ was considered significant. The datasets used and analysed during the current study available from the corresponding author on reasonable request.

\section{Results}

\section{Macroscopic features}

Of the 36 samples, 24 (67\%) had tears present in the hip abductors (either the gluteus medius, minimus or both). Of these 24 samples with tears present, 11 (46\%) were isolated gluteus minimus tears, $5(21 \%)$ were isolated gluteus medius tears and 8 (33\%) involved the tendon of both muscles. Overall, the most common macroscopic finding was an isolated gluteus minimus tear, followed by tears involving both the gluteus minimus and medius.

In the 13 samples where a gluteus medius tear was identified, 11 tears were found in the anterior/middle portion of the tendon which inserts at the lateral facet of the greater trochanter. Only 2 small partial tears were found in the posterior portion of the gluteus medius. This portion inserts separately through a cord-like tendon at the supero-posterior facet of the greater trochanter. In both cases, the tears were less than $5 \mathrm{~mm}$ and no other abnormalities were identified in either the gluteus medius or minimus. In the gluteus minimus, all tears were found anteriorly, adjacent to the attachment of the gluteus medius tendon (Fig. 3).

Both complete and partial tears were found in the gluteus medius and minimus tendons. Partial tears were only observed on the under surface of the tendons. All tears were found in the distal $1 \mathrm{~cm}$ of tendon, while no tears were observed in either the gluteus medius or minimus tendons proximally. Interestingly, three samples with a complete gluteus minimus tear were also associated with 


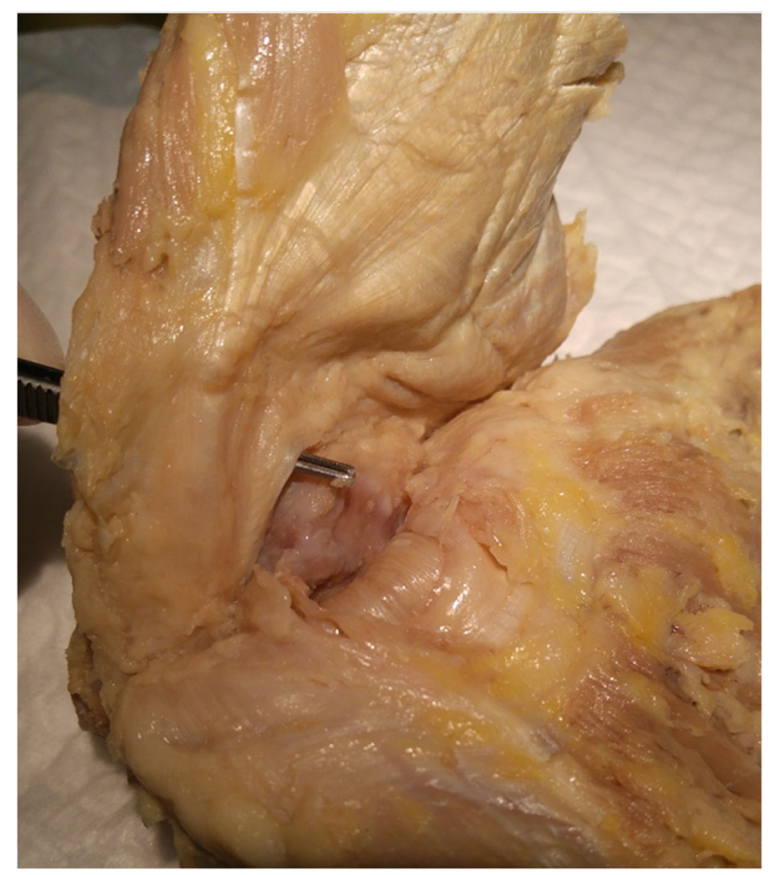

Fig. 3 En-bloc sample showing complete tear through gluteus minimus and a partial tear through the overlying gluteus medius

partial under surface tears in the gluteus medius tendon immediately adjacent to the gluteus minimus tear.

The average width of a complete gluteus medius tear was $15.6 \mathrm{~mm}$ (SD 7.2) and $9.8 \mathrm{~mm}$ (SD 6.5) for partial tears. The average width of a complete gluteus minimus tear was $7.9 \mathrm{~mm}$ (SD 4.3) and $6.5 \mathrm{~mm}$ (SD 3.7) for partial tears. The differences in size between complete and partial tears was not statistically significant $(p=0.24)$.

Other macroscopic features were compared between samples with and without tears (Table 1). Of samples with complete tears, $89 \%$ were observed to have gross fatty atrophy of the related muscle. Delamination of the tendon was observed predominantly in samples with complete or partial tears. Bony changes (spur formation) were only observed in one sample with a complete tear.

\section{Microscopic features}

\section{Lateral insertion of gluteus medius}

Comparisons were made between normal samples, samples with partial tears and samples with complete tears.
The Modified Movin's score was significantly different in normal (3.2), partial tear (8.6) and complete (8.9) tear samples (ANOVA $p=0.0005$ ) (Fig. 4). Further post-hoc analysis separately demonstrated higher degeneration scores in the samples with complete $(p=0.0049)$ and partial tears $(p=0.0099)$ when compared to those with no tears (Table 2). The difference in degeneration between complete and partial tears was not statistically significant.

In the enthesis, the semi-quantitative degeneration scores (Additional file 1: Appendix 2) in normal (3.0), partial (7.4) and complete (7.1) tear samples were significantly different (ANOVA $\mathrm{p}=0.0011$ ). Again, posthoc analysis demonstrated significantly higher scores in samples with both complete $(p=0.011)$ and partial tears $(0.0075)$ when compared to those with no tears (Table 2).

When evaluating the degeneration scores in the superficial, middle and deep layers of the tendon, no significant difference between the layers were found in samples without tears $(p=0.19)$. However, in samples with complete and partial tears, the deep and middle layers scored significantly higher when compared to the superficial layer ( $p=0.0002$, Table 3$)$. A similar pattern was also seen in the enthesis, where samples with tears were found to have significantly higher degeneration scores in the middle and deep layers (Table 4). In the middle and deep layers, significant differences in degeneration scores were found between samples with tears and no tears, where this was not evident in the superficial layer of the enthesis.

Two-way ANOVA was unable to detect a significant interaction between layer examined and the presence of tears in either the tendon (interaction $\mathrm{p}=0.14$ ) or the enthesis (interaction $p=0.082$ ).

\section{Supero-posterior insertion of gluteus medius}

In both samples where an isolated partial tear was found in the supero-posterior insertion, minimal degenerative changes were observed; in one sample, minimal regional variation in cellularity was found in the mid-substance of the tendon. The other sample displayed mild nuclei rounding and vascular infiltration, again in the midsubstance of the tendon. The enthesis of both samples exhibited no degenerative changes.

Table 1 Associated features of hip abductor tendon tears

\begin{tabular}{lllll}
\hline & Complete tear & Partial tear & Normal & p-value \\
\hline Fatty atrophy of muscle & $8(89 \%)$ & $2(14 \%)$ & 0 & $<0.001$ \\
Delaminated & $5(56 \%)$ & $8(57 \%)$ & $1(10 \%)$ & 0.030 \\
Bony changes & $1(11 \%)$ & 0 & 0 & NS \\
\hline
\end{tabular}




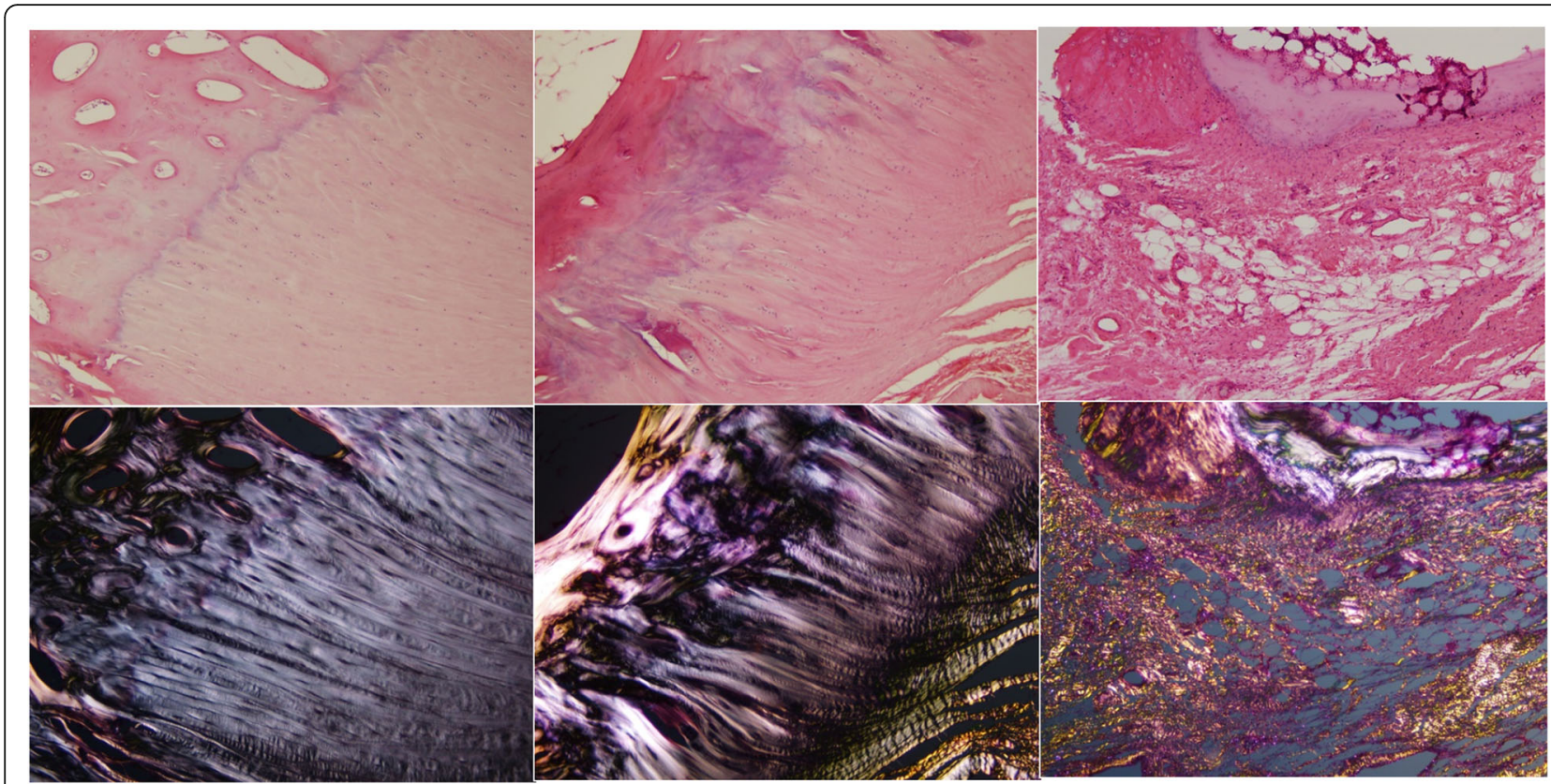

Fig. $4 \mathrm{H} \& \mathrm{E}$ stained slides through the gluteus medius bone tendon junction. Top images transmitted light, bottom images polarised light. Left normal sample, middle - area adjacent to partial tear, right - area of complete tear. Samples demonstrate progressive degenerative changes

In samples of the supero-posterior insertion where a concurrent lateral insertion tear was present, the average degeneration score was 4.9 (SD 2.6) in the tendon and 3.8 (SD 2.2) in the enthesis. In contrast, the average degeneration scores in the same samples at the lateral insertion was 9.0 (SD 1.7) in the tendon and 7.6 (SD 2.0) in the enthesis. These differences were statistically significant $(p=0.012$ and $p=$ 0.013 respectively). No degenerative changes were found in the supero-posterior gluteus medius when tears were not present in the lateral portion of gluteus medius.

\section{Gluteus minimus}

In samples where a complete or partial tear were identified, the average modified Movin's score was 13.4 and 11.1 respectively compared to 3.0 in normal samples. These differences were statistically significant $(p=$ 0.0095) (Table 5). Again, enthesis involvement was seen in all samples with tears. The average enthesis degeneration score was 10.5 in complete tears, 9.6 in partial tears and 3.3 in normal samples $(p=0.021)$.

\section{Discussion}

This study is the largest series to date to examine hip abductor tendons in a cadaveric population. We demonstrated that the majority of tears involved the insertion of anterior/middle gluteus medius and the gluteus minimus. Microscopically, degeneration at both the tendon and enthesis underlies the observed macroscopic tears. Lastly, we found more advanced degeneration in the deeper layers of the tendon and enthesis, suggesting a potential pathomechanism of gluteus medius tears.

While many previous studies reported tears in the anterior gluteus medius, only a few have examined the gluteus minimus [26-28]. In the present study, gluteus minimus tears were observed more commonly than gluteus medius tears. Furthermore, all complete tears of the gluteus medius were associated with a concurrent gluteus minimus tear. This finding has clinical importance, as both ultrasound and MRI are poor at identifying

Table 2 Histology tendon and enthesis scores for lateral insertion of gluteus medius

\begin{tabular}{lllll}
\hline & Tendon (SD) & p-value (post hoc) & Enthesis (SD) & P-value (post hoc) $^{\mathbf{a}}$ \\
\hline Complete Tear & $8.9(2.0)$ & 0.0049 & $7.1(1.5)$ & 0.011 \\
Partial Tear & $8.6(1.7)$ & 0.0099 & $7.4(1.9)$ & 0.0075 \\
No Tear & $3.2(1.8)$ & reference & $3.0(2.0)$ & reference \\
p-value (ANOVA) & 0.0005 & & 0.0011 & \\
\hline
\end{tabular}

Post hoc for multiple comparisons 
Table 3 Histology scores for lateral gluteus medius tendon layers

\begin{tabular}{lllll}
\hline & Superficial & Middle & Deep & p-value* \\
\hline Tears & $6.0(2.4)$ & $8.7(2.2)$ & $11.5(3.0)$ & 0.0002 \\
No tears $^{*}$ & $2.0(1.7)$ & $3.4(1.6)$ & $4.2(2.5)$ & 0.19 \\
p-value $^{+}$ & 0.0018 & 0.00050 & 0.00031 &
\end{tabular}

${ }^{+} p$-value for tears vs no tears for each tendon layer

${ }^{*} p$-value for difference in layers for samples with and without tears

Two way ANOVA - column factor (tendon layer) $p=0.0002$, row factor

(presence of tears) $p<0.0001$, interaction $p=0.14$

gluteus minimus tears when a gluteus medius tear was also present $[1,26]$.

The pattern of disease identified also provides evidence that hip abductor tears may originate from the gluteus minimus. Previous electromyography and functional studies found increased loads in the gluteus minimus during the single stance phase of gait, particularly as the hip moves into adduction and extension [29, 30]. This "overload" phenomenon predominantly affects the gluteus minimus and not the gluteus medius [31]. Furthermore, the area of gluteus minimus deep to gluteus medius may experience increased compressive loads [8, 32]. This combination of increased tensile and compressive forces is a known risk factor for the development of tendinopathy and tears [32-34]. Functionally, the gluteus minimus acts synergistically with the anterior gluteus medius to stabilise the pelvis during gait and facilitate forward contralateral rotation of the pelvis [29, $30,35,36]$. This shared function may also help to explain the large number of tears observed in both the gluteus minimus and the adjacent anterior gluteus medius tendons. In the current study, the majority of tears were found at the lateral insertion of the gluteus medius, with only two minor tears found at the supero-posterior insertion. This suggests that the supero-posterior insertion functions separately and is not involved in the degenerative process observed at the lateral insertion.

We identified a strong association between complete tendon tears and fatty atrophy of the gluteus medius and minimus. This has been reported in a number of imaging studies [37-39]. Once established, muscle atrophy is often irreversible and therefore, repair of the tendon

Table 4 Enthesis scores for lateral gluteus medius layers

\begin{tabular}{lllll}
\hline & Superficial & Middle & Deep & p-value* $^{*}$ \\
\hline Tears & $4.0(2.7)$ & $5.9(2.3)$ & $8.3(3.0)$ & 0.0030 \\
No tears & $2.4(1.8)$ & $2.8(2.2)$ & $3.7(2.6)$ & 0.54 \\
p-value $^{+}$ & 0.28 & 0.0029 & 0.0004 &
\end{tabular}

${ }^{+} p$-value for tears vs no tears for each tendon layer

${ }^{*} p$-value for difference in layers for samples with and without tears

ANOVA - column factor (tendon layer) $p=0.014$, row factor (presence of tears) $p<0.0001$, interaction $p=0.0815$ may result in poor clinical improvement post-surgery and must be undertaken with caution [40, 41]. This raises the importance of early detection and repair of partial gluteus medius and minimus tears.

Microscopically, the present study has confirmed degeneration as the underlying pathology in hip abductor tendon tears. This is similar to histological findings in rotator cuff, Achilles and patella tendon tears [24, 4244 ]. In the hip abductor tendons, a study by Fearon et al. examined tendon samples obtained intraoperatively at the time of gluteus medius repair. Given the small number of samples, they were only able to report qualitative degenerative change. Furthermore, the degree of degeneration was not specified and the enthesis was not examined [1]. Using semiquantitative scores, we found significant degeneration in not only the tendon but also the enthesis when tears were present in both the gluteus medius and minimus. Given the importance of the enthesis in load distribution, it is not surprising that degeneration in both tissue types contribute to tendon tears [21]. Interestingly, we were unable to demonstrate significant degenerative changes in two small, partial tears in the posterior insertion of gluteus medius. However, a larger sample size is required for definitive conclusions.

An important finding of the study was that microscopically, degenerative changes are concentrated in the deeper layers of the tendon and enthesis. In both tissue types, samples with tears exhibited higher degeneration scores in the deep and middle layers compared to the superficial layer. This difference was not seen in samples without tears. However, two-way ANOVA did not find a significant interaction between tear presence and tendon layer degeneration. This is likely due to early degenerative changes that maybe be present in macroscopically normal tendons. Degeneration in the deeper layers of the tendon (articular side) have also been observed in rotator cuff tears $[44,45]$. The hip abductor and the rotator cuff share a number of similarities in their anatomy and function $[5,8,36]$. As such, the intrinsic mechanism of rotator cuff tendinopathy may apply to hip abductor tendon tears. The degeneration seen in the deeper layers may be secondary to the deeper fibres experiencing increased mechanical loads compared to the outer fibres, especially in adduction and small angles of abduction [32]. This theory is supported by both intraoperative findings in both the hip abductor and the rotator cuff [46-48]. Histologically, rotator cuff tears exhibit significantly more advanced degeneration in the deeper layers of the tendon [21, 44, 47, 48]. This again mirrors the findings of our study. Given the similarities between hip abductor and the rotator cuff tears, novel surgical methods, materials and biological augments maybe equally applicable to both problems. 
Table 5 Histology and enthesis scores for gluteus minimus insertion

\begin{tabular}{lllll}
\hline & Tendon (SD) & p-value (post hoc) & Enthesis (SD) & p-value (post hoc) \\
\hline Complete Tear & $13.4(1.7)$ & 0.012 & $10.5(1.7)$ & 0.025 \\
Partial Tear & $11.1(2.4)$ & 0.2 & $9.6(1.1)$ & 0.16 \\
No Tear & $3.0(1.8)$ & reference & $3.3(1.5)$ & reference \\
p-value (ANOVA) & 0.0095 & & 0.021 & \\
\hline
\end{tabular}

With the supero-posterior insertion of gluteus medius and the gluteus minimus insertion, we did not grade layers of the samples separately. This was due to the smaller cross-sectional area of these insertions compared to the lateral insertion of gluteus medius. Future studies evaluating these areas may employ longitudinal sectioning to better appreciate the difference in degeneration between the layers [44].

A limitation of our study is that the tissue samples were obtained from cadavers with incomplete past medical histories. From patient discharge summaries and death certificates that were available, it was not possible to ascertain accurate information regarding the presence or absence of lateral hip pain and gait abnormalities. However, cadaveric studies have several advantages. Firstly, detailed macroscopic examination was possible as the area of interest was removed enbloc. The insertion can be closely examined from both its superficial and deep surfaces without field of view limitations. Secondly, we were able to identify degenerative changes in both the tendon and enthesis by detailed histological examination of the entire tendon-bone unit. This provided greater insight into the pathological basis of disease which is not possible with imaging studies.

Our results have numerous implications for surgical repair. Firstly, we confirmed that the majority of gluteus medius tears involved the deep surface of the tendon. Therefore, this area must be specifically examined and addressed during repair. Secondly, we found higher than expected incidence of gluteus minimus tears that often co-exist with gluteus medius tears. Therefore, during surgical repair of the gluteus medius, the gluteus minimus should be carefully examined and repaired if torn. Lastly, the development of new biological materials for tendon repair requires improved understanding of the pathological features of abductor tendon tears. In our study, we have visualised and identified both tendon and enthesis degeneration as the key feature in hip abductor tendinopathy. Hence, novel materials and biologics must target both tissue types to improve healing following surgery.

In conclusion, we found degenerative changes are the underlying pathology in hip abductor tendon tears. Both the macroscopic and microscopic features of degeneration were predominantly observed in the deep layers of the tendons. These findings are important for guiding surgical repair techniques and to aid the development of novel materials and biologics in order to improve surgical outcomes.

\section{Supplementary Information}

The online version contains supplementary material available at https://doi. org/10.1186/s12891-020-03784-3.

Additional file 1: Appendix 1. Modified Movin's score for

tendinopathy. Appendix 2. Enthesis scoring criteria, maximum score 15, minimum score 0 .

\section{Abbreviations}

H\&E: Haematoxylin and Eosin; ANOVA: Analysis of Variance; SD: Standard deviation; MRI: Magnetic resonance imaging

\section{Acknowledgements}

Nil.

\section{Authors' contributions}

MZ participated in study design, dissection of specimens and tissue processing, acquisition of data, interpretation of data, drafting of the article, revision of the manuscript and approval of submitted manuscript. BS participated in study design, tissue processing, acquisition of data, drafting of the article and approval of submitted manuscript. SK participated in study design, dissection of specimens and tissue processing, revision of the manuscript and approval of submitted manuscript. DM participated in study conception and design, analysis, drafting of the article and critical revision of the manuscript and approval of submitted manuscript. PR participated in study design, dissection of specimens and tissue processing, revision of the manuscript and approval of submitted manuscript. SM participated in study design, dissection of specimens and tissue processing, revision of the manuscript and approval of submitted manuscript. JC participated in study conception and design, analysis and interpretation of data, critical revision of the manuscript and approval of submitted manuscript. JM participated in study conception and design, planning of surgical dissection and dissection of specimens, analysis and interpretation of data, critical revision of the manuscript and approval of submitted manuscript.

\section{Funding}

The authors would like to acknowledge the New Zealand Orthopaedic Association (Grant number 371455) and the Health Research Council of New Zealand (Grant number 3714609) for funding experimental costs in this study.

Availability of data and materials

All data generated during this study are included in this published article.

Ethics approval and consent to participate

All tissue was obtained from embalmed human cadavers bequeathed for teaching and research to the University of Auckland, New Zealand, under the acquisition of Human Tissue Act (2008). The study was approved by The Human Tissue Committee, University of Auckland, New Zealand. 


\section{Consent for publication}

Not applicable.

\section{Competing interests}

The authors declare that they have no competing interests.

\section{Author details}

'Bone and Joint Laboratory, University of Auckland, 85 Park Road, Grafton 1023, New Zealand. ${ }^{2}$ Department of Orthopaedic Surgery, Auckland City Hospital, 2 Park Road, Grafton, New Zealand. ${ }^{3}$ Department of Anatomy and Medical Imaging, University of Auckland, 85 Park Road, Grafton, New Zealand.

Received: 25 April 2020 Accepted: 10 November 2020

Published online: 26 November 2020

\section{References}

1. Fearon AM, Scarvell JM, Cook JL, Smith PN. Does ultrasound correlate with surgical or histologic findings in greater trochanteric pain syndrome? A pilot study. Clin Orthop Relat Res. 2010;468:1838-44.

2. Albers IS, Zwerver J, Diercks RL, Dekker JH, Van den Akker-Scheek I. Incidence and prevalence of lower extremity tendinopathy in a dutch general practice population: a cross sectional study. BMC Musculoskelet Disord. 2016;17:16

3. Redmond J, Chen A, Domb B. Greater trochanteric pain syndrome. J Am Acad Orthop Surg. 2016;24:231-40.

4. Berry DJ, Sierra RJ, Hanssen AD, Sheth NP, Paprosky WG, Della Valle CJ. AAHKS symposium: state-of-the-art management of tough and unsolved problems in hip and knee arthroplasty. J Arthroplast. 2016:31:7-15.

5. Bunker TD, Esler CN, Leach WJ. Rotator-cuff tear of the hip. J Bone Joint Surg Br. 1997;79:618-20.

6. Howell GE, Biggs RE, Bourne RB. Prevalence of abductor mechanism tears of the hips in patients with osteoarthritis. J Arthroplast. 2001;16:121-3.

7. Board TN, Hughes SJ, Freemont AJ. Trochanteric bursitis: the last great misnomer. Hip Int. 2014;24:610-5.

8. Hendry J, Biant LC, Breusch SJ. Abductor mechanism tears in primary total hip arthroplasty. Arch Orthop Trauma Surg. 2012;132:1619-23.

9. Garcia FL, Picado CHF, Nogueira-Barbosa MH. Sonographic evaluation of the abductor mechanism after total hip arthroplasty. J Ultrasound Med. 2010;29:465-71.

10. Capogna BM, Shenoy K, Youm T, Stuchin SA. Tendon disorders after total hip arthroplasty: evaluation and management. J Arthroplasty. 2017;32(10): 3249-55.

11. Connell DA, Bass C, Sykes CJ, Young D, Edwards E. Sonographic evaluation of gluteus medius and minimus tendinopathy. Eur Radiol. 2003;13:1339-47.

12. Miozzari HH, Dora C, Clark JM, Nötzli HP. Late repair of abductor avulsion after the transgluteal approach for hip arthroplasty. J Arthroplasty. 2010; 25(450):457 e1.

13. Byrd JWT, Jones KS. Endoscopic repair of hip abductor tears: outcomes with two-year follow-up. J Hip Preserv Surg. 2017;4:80-4.

14. Lübbeke A, Kampfen S, Stern R, Hoffmeyer P. Results of surgical repair of abductor avulsion after primary total hip arthroplasty. J Arthroplast. 2008;23:694-8.

15. Ebert JR, Bucher TA, Ball SV, Janes GC. A review of surgical repair methods and patient outcomes for gluteal tendon tears. Hip Int. 2015;25:15-23.

16. Whiteside LA. Surgical technique: transfer of the anterior portion of the gluteus maximus muscle for abductor deficiency of the hip. Clin Orthop Relat Res. 2012;470:503

17. Robertson WJ, Gardner MJ, Barker JU, Boraiah S, Lorich DG, Kelly BT Anatomy and dimensions of the gluteus medius tendon insertion. Arthroscopy. 2008;24:130-6.

18. Flack NMS, Nicholson HD, Woodley SJ. The anatomy of the hip abductor muscles. Clin Anat. 2014;27:241-53.

19. Benjamin M, Ralphs JR. Entheses - the bony attachments of tendons and ligaments. Ital J Anat Embryol. 2001;106:151-7.

20. Loppini M, Longo UG, Niccoli G, Khan WS, Maffulli N, Denaro V. Histopathological scores for tissue-engineered, repaired and degenerated tendon: a systematic review of the literature. Curr Stem Cell Res Ther. 2015; 10:43-55.
21. Rossetti L, Kuntz LA, Kunold E, Schock J, Müller KW, Grabmayr H, et al. The microstructure and micromechanics of the tendon-bone insertion. Nat Mater. 2017;16:664-70.

22. Thangarajah T, Henshaw F, Sanghani-Kerai A, Lambert SM, Blunn GW Pendegrass CJ. The effectiveness of demineralized cortical bone matrix in a chronic rotator cuff tear model. J Shoulder Elb Surg. 2017;26:619-26.

23. Benjamin M, Ralphs JR. Fibrocartilage in tendons and ligaments--an adaptation to compressive load. J Anat. 1998;193(Pt 4):481-94.

24. Maffulli N, Barrass V, Ewen SW. Light microscopic histology of achilles tendon ruptures. A comparison with unruptured tendons. Am J Sports Med. 2000;28:857-63.

25. Rufai A, Ralphs JR, Benjamin M. Structure and histopathology of the insertional region of the human achilles tendon. J Orthop Res. 1995;13:585-93.

26. Makridis KG, Lequesne M, Bard $H$, Djian P. Clinical and MRI results in 67 patients operated for gluteus medius and minimus tendon tears with a median follow-up of 4.6 years. Orthop Traumatol Surg Res. 2014;100:849-53.

27. Laban MM, Weir SK, Taylor RS. 'Bald trochanter' spontaneous rupture of the conjoined tendons of the gluteus medius and minimus presenting as a trochanteric bursitis. Am J Phys Med Rehabil. 2004;83:806-9.

28. Kingzett-Taylor A, Tirman PF, Feller J, McGann W, Prieto V, Wischer T, et al. Tendinosis and tears of gluteus medius and minimus muscles as a cause of hip pain: MR imaging findings. Am J Roentgenol. 1999;173: 1123-6.

29. Gottschalk F, Kourosh S, Leveau B. The functional anatomy of tensor fasciae latae and gluteus medius and minimus. J Anat. 1989;166:179-89.

30. Semciw Al, Pizzari T, Murley GS, Green RA. Gluteus medius: an intramuscular EMG investigation of anterior, middle and posterior segments during gait. J Electromyogr Kinesiol. 2013;23:858-64.

31. Kumagai M, Shiba N, Higuchi F, Nishimura $H$, Inoue A. Functional evaluation of hip abductor muscles with use of magnetic resonance imaging. J Orthop Res. 1997;15:888-93.

32. Grimaldi A, Mellor R, Hodges P, Bennell K, Wajswelner $H$, Vicenzino B. Gluteal tendinopathy: a review of mechanisms, assessment and management. Sports Med. 2015:45:1107-19.

33. Kjaer M, Langberg $H$, Magnusson SP. The pathogenesis of tendinopathy: balancing the response to loading. Nat Rev Rheumatol. 2010;6:262-8.

34. Basso O, Amis AA, Race A, Johnson DP. Patellar tendon fiber strains: their differential responses to quadriceps tension. Clin Orthop Relat Res. 2002: 246-53.

35. Semciw Al, Green RA, Murley GS, Pizzari T. Gluteus minimus: an intramuscular EMG investigation of anterior and posterior segments during gait. Gait Posture. 2014;39:822-6.

36. Al-Hayani A. The functional anatomy of hip abductors. Folia Morphol (Warsz). 2009;68:98-103.

37. Chi AS, Long SS, Zoga AC, Read PJ, Deely DM, Parker L, et al. Prevalence and pattern of gluteus medius and minimus tendon pathology and muscle atrophy in older individuals using MRI. Skelet Radiol. 2015:44:1727-33.

38. Pfirrmann CW, Chung CB, Theumann NH, Trudell DJ, Resnick D. Greater trochanter of the hip: attachment of the abductor mechanism and a complex of three bursae--MR imaging and MR bursography in cadavers and MR imaging in asymptomatic volunteers. Radiology. 2001:221:469-77.

39. Kong A, Van der Vliet A, Zadow S. MRI and US of gluteal tendinopathy in greater trochanteric pain syndrome. Eur Radiol. 2007;17:1772-83.

40. Davies JF, Stiehl JB, Davies JA, Geiger PB. Surgical treatment of hip abductor tendon tears. J Bone Joint Surg. 2013:95:1420-5.

41. Lachiewicz PF. Abductor tendon tears of the hip: evaluation and management. J Am Acad Orthop Surg. 2011;19:385-91.

42. Longo UG, Franceschi F, Ruzzini L, Rabitti C, Morini S, Maffulli N, et al. Histopathology of the supraspinatus tendon in rotator cuff tears. Am Sports Med. 2008;36:533-8.

43. Maffulli N, Del Buono A, Spiezia F, Longo UG, Denaro V. Light microscopic histology of quadriceps tendon ruptures. Int Orthop. 2012; 36:2367-71.

44. Hashimoto T, Nobuhara K, Hamada T. Pathologic evidence of degeneration as a primary cause of rotator cuff tear. Clin Orthop Relat Res (1976-2007). 2003:415:111-20.

45. Longo UG, Franceschi F, Ruzzini L, Rabitti C, Morini S, Maffulli N, et al. Light microscopic histology of supraspinatus tendon ruptures. Knee Surg Sports Traumatol Arthrosc. 2007;15:1390-4

46. Domb BG, Botser I, Giordano BD. Outcomes of endoscopic gluteus medius repair with minimum 2-year follow-up. Am J Sports Med. 2013;41:988-97. 
47. Seitz AL, McClure PW, Finucane S, Boardman ND, Michener LA. Mechanisms of rotator cuff tendinopathy: Intrinsic, extrinsic, or both? Clin Biomech (Bristol, Avon). 2011;26:1-12.

48. Huang C, Wang VM, Pawluk RJ, Bucchieri JS, Levine WN, Bigliani LU, et al. Inhomogeneous mechanical behavior of the human supraspinatus tendon under uniaxial loading. J Orthop Res. 2005;23:924-30.

\section{Publisher's Note}

Springer Nature remains neutral with regard to jurisdictional claims in published maps and institutional affiliations.

Ready to submit your research? Choose BMC and benefit from:

- fast, convenient online submission

- thorough peer review by experienced researchers in your field

- rapid publication on acceptance

- support for research data, including large and complex data types

- gold Open Access which fosters wider collaboration and increased citations

- maximum visibility for your research: over $100 \mathrm{M}$ website views per year

At $\mathrm{BMC}$, research is always in progress.

Learn more biomedcentral.com/submissions 